\title{
Effect of Weave Structure on the Ornamentation of Denim Fabrics
}

\author{
Mohammad Zakaria ${ }^{1 *}$, Shafiqul Islam², SM Bin Rafat Hasan Chowdhury ${ }^{3}$, Md Kamal Hossen Chowdhury ${ }^{4}$, Abdullah \\ Al-Mamun ${ }^{5}$ and Md Nazmul Islam ${ }^{6}$
}

${ }^{1}$ Department of Textile Engineering, Dhaka University of Engineering \& Technology, Gazipur, Bangladesh

${ }^{2}$ Department of Textile Engineering, Dhaka University of Engineering \& Technology, Gazipur, Bangladesh

${ }^{3}$ AGM plant, Amber Denim Ltd. Rajendrapur, Gazipur, Bangladesh

${ }^{4}$ Sr DGM, Thermax Yarn Dyed Fabrics Ltd, Norshingdi, Bangladesh

${ }^{5}$ Designation Executive, Central R \& D, Talha Fabrics Ltd. VawalMirzapur, Gazipur, Bangladesh

${ }^{6}$ Executive (R \& D), Thermax Yarn Dyed Fabrics Ltd, Norshingdi, Bangladesh

Received: 畊 April 26, 2018; Published: 㘹 May 01, 2018

*Corresponding author: Mohammad Zakaria, Department of Textile Engineering, Dhaka University of Engineering \& Technology, Gazipur, Bangladesh, Email: zakariate@duet.ac.bd

\begin{abstract}
Denim is the term which conquers the modern world with spectacular fashion appeal. Previously the denim cloth was hardly found as fashionable wear however, it is the more common item in modern fashion trend. So, the diversification of denim fabric is the crucial demand of apparel industry. A numerous attempt especially washing treatment has been carried out in order to make denim fabrics more attractive and fashionable however, those are resulting fabric the strength and serviceability reduction. Six different decorative weaves were designed by using point carre software and $100 \%$ cotton denim fabrics were produced with same specification by using dobby loom. Visual appearance, tear strength, tensile strength, oz/yd ${ }^{2}$, shrinkage $\%$ and spirality $\%$ of decorative denim are examined and compared with the conventional denim fabric manufactured with same specification. Visual appearance of decorative denim is so attractive after performing only normal wash. The tear strength and fabric weight (oz/yd $\left.\mathrm{d}^{2}\right)$ of decorative denim is higher than conventional denim without some exception. The tensile strength of decorative \& conventional denim is more or less same. However, due to the loose structure and long float of weave, decorative denim shows higher shrinkage $\%$ and spirality\%.
\end{abstract}

Keywords: Denim; Fabric; Weaves Structure; Fashion; Design Development etc.

\section{Introduction}

Denim was traditionally colored blue with indigo dye to make blue "jeans," though "jean" then denoted a different, lighter cotton textile (Shalini). In general denim is made by cotton and twill weave stiff fabric where the warp yarns are dyed with indigo which remains on the surface [1,2]. Traditional blue denim is a cotton twill fabric, of most indigo denim that only the warp threads are dyed, whereas the color of weft threads remains plain white. As a result of the warp-faced twill weaving, one side of the fabric shows the colored warp threads and the other side shows the white weft threads. The available traditional weave formula of denim fabrics are $2 / 1,3 / 1$ etc. The warp and filling yarns of denim fabrics range from $7 \mathrm{~s}$ to $16 \mathrm{~s}$ and $8^{\mathrm{s}}$ to $23^{\mathrm{s}}$ respectively [3].

Now a day's Denim is considered as fashion icon for youth and number of people increase day by day toward the denim [4]. The demand and market of denims are expanding very rapidly. It was observed that $50 \%$ of people under 60 have preferred denim products during their lives. $90 \%$ of the people around 14 and 19 ages and $70 \%$ of the people around 20 and 29 ages stated that 
denim products were crucial for their wearing experiences. Its usage has always an increase trend and it is thought that making it more comfortable and improving some properties [5]. As lifestyles change, the denim producer keeps attention on fibers, finishing techniques, application treatments and end-uses. In addition, to make the denim more appealing to its customer, different types of washing, finishing and after treatment has performed [6]. Mezarcioz andToksoz have investigated the effect of different washing processes on various performance and surface properties of denim fabrics [7]. Most of this reduces the strength and lifetime of the fabrics. Moreover, some common washing process like stone wash, enzyme wash reduces the strength of fabric. have found that the hard stone wash is suitable for heavy weight fabrics only [8]. Normally the stone wash is done by physically abrading on fabric surface and the enzyme wash is providing the chemical abrasion only. During enzyme washing certain amount of indigo dye and cellulose fibers from the surface of the fabric are removed [9]. Special care must be required during denim bleaching as the harm of hypochlorite to cotton increasing with rise of temperature, the damage to the cotton discoloration comes is very fast.

So this type of washing and finishing has reduced the strength of denim fabric. But strength of the fabric is an important property that decides and influences all other performance of the fabric. Consideration of the strength of the fabric is very essential while selecting the appropriate fabric for the intended garment as well as the fiber properties are indirectly affect to fabric properties [10]. To this end, washing treatment obviously impart a detrimental effect on fabric strength and legibility. On the other hand, the attempts to decorate the denim fabric without washing are too limited. With this background, the main goal of the study is to ornament denim fabric by using different weave structure with long float and irregular weave arrangement. In addition, a comparative study has been carried out between the decorative denim fabric and denim fabric with conventional weave in respect to their visual appearance, tear strength, tensile strength, oz $/ \mathrm{yd}^{2}$, shrinkage $\%$ and spirality $\%$.

\section{Materials and Methods}

\section{Materials}

$100 \%$ cotton indigo dyed warp of 16 s and 16 s raw cotton weft yarn were collected from Amber Denim Ltd. Gazipur Bangladesh. The mentioned warp yarn was sized and arrange in a weavers beam with 600 meters length. The weavers beam was prepared also considering the targeted fabric specification

$$
\frac{16 \times 16}{90 \times 60} \times 62^{n}
$$

\section{Weave Design Development}

Various types of weave design were developed by using Point carre weaving CAD software at Weaving CAD lab of department of textile engineering, Dhaka University of Engineering and Technology, Gazipur, Bangladesh. The simulated view of developed fabrics was observed and chose the best six structure shown in
Figure 1. The selected designs were prepared with twelve healed shaft and straight drafting shown in Figure 2.

\section{Weaving and Sample Preparation}

Woven fabric with $\frac{16 \times 16}{90 \times 60} \times 62^{n}$ specification was manufacture by using prepared weavers beam. The weaving operation was done by Picanol GT-Max rapier dobby loom at Thermax Yarn Dyed Fabrics Ltd. Narsingdi, Bangladesh. After weaving the six selected decorative denim fabric three conventional denim fabrics such as $1 / 1$ plain, 2/1\& $3 / 1$ twill were also produced with same specification and loom parameters. Then the grey fabric was collected from loom and the primary inspection was done then the fabric was subjected to required wet treatment with normal wash (Figures $1 \& 2$ ).

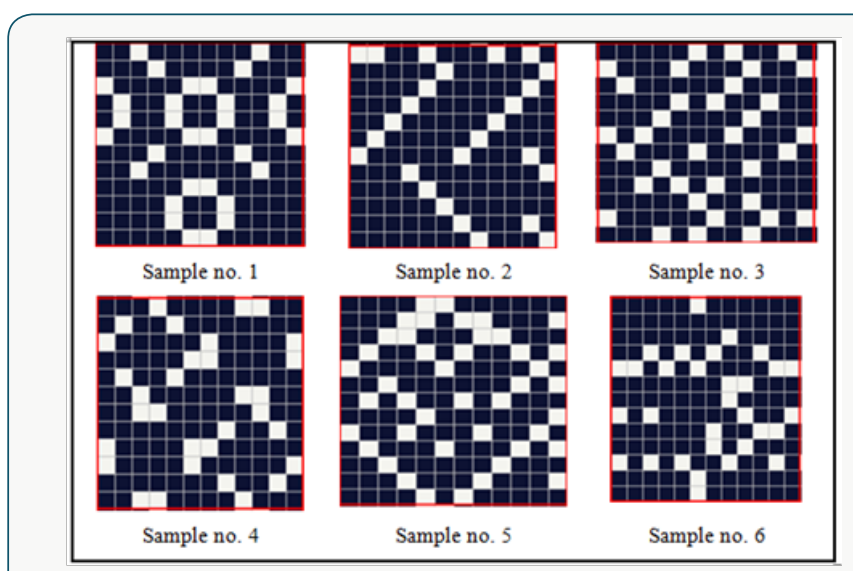

Figure 1: Weave plan of decorative denim fabric.

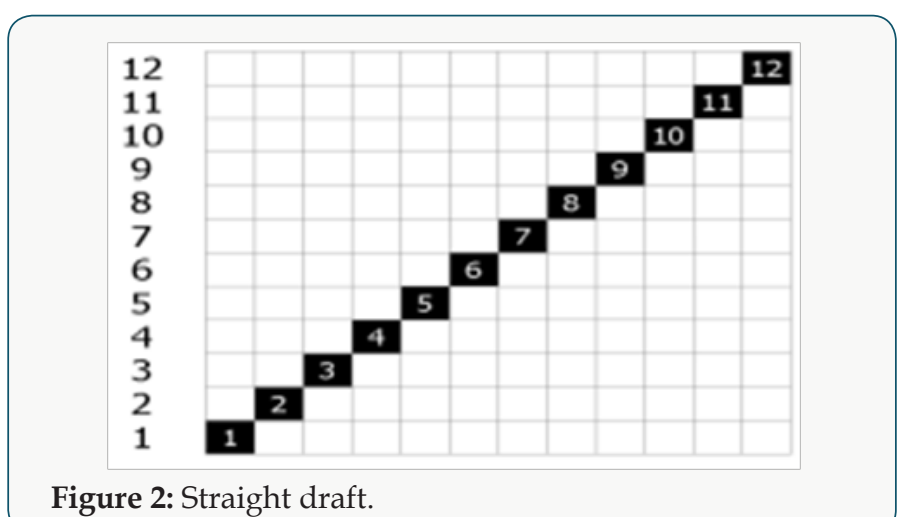

\section{Test Preparation}

After finishing the prepared fabric was conditioned under standard atmosphere for 24 hours before testing in accordance with ISO 139.

\section{Testing Procedure}

After conditioning the tear strength test of the specimen was carried out by following ISO 13937-1 method. The result was checked in fact within the zone between $15 \%$ and $85 \%$ of the full scale used. The tensile strength of the fabric was tested with accordance to ISO 13934-1 and ISO 3801standard method was obeying to determine the unit weight of fabric. The shrinkage and spirality of fabric were determined according to the standard 
method ISO 5077 and AATCC 179 respectively. Each test has conducted very carefully and makes average from five different test results.

\section{Results and Discussion}

\section{Assessment of Visual Appearance}

Denim fabric is mainly supposed to be fashionable wire and expanding its application area day by day. In case of fashion clothing, the surface appearance is the key of consumer attraction. The visual appearance of some selected finished decorative denim fabric care shown in (Figure 3). Here, a promising effect is pictured on the fabric surface after performing normal washing. However, in order to create the same effect on conventional denim fabric, it required more number of washing treatment which consume extra chemical causing increase cost and environmental threat.

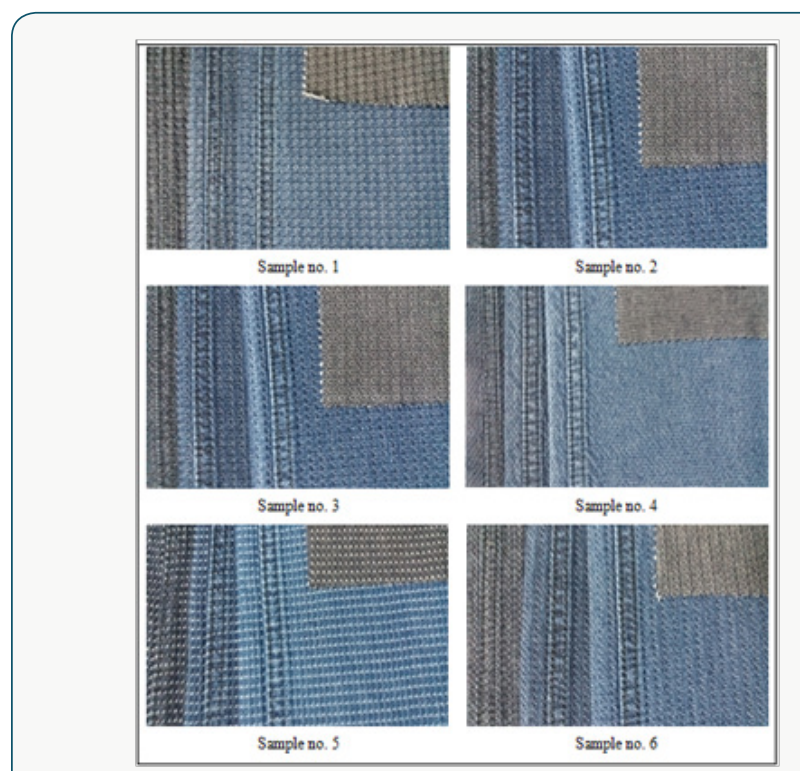

Figure 3: Visual appearance of the samples.

\section{Assessment of Tear Strength}

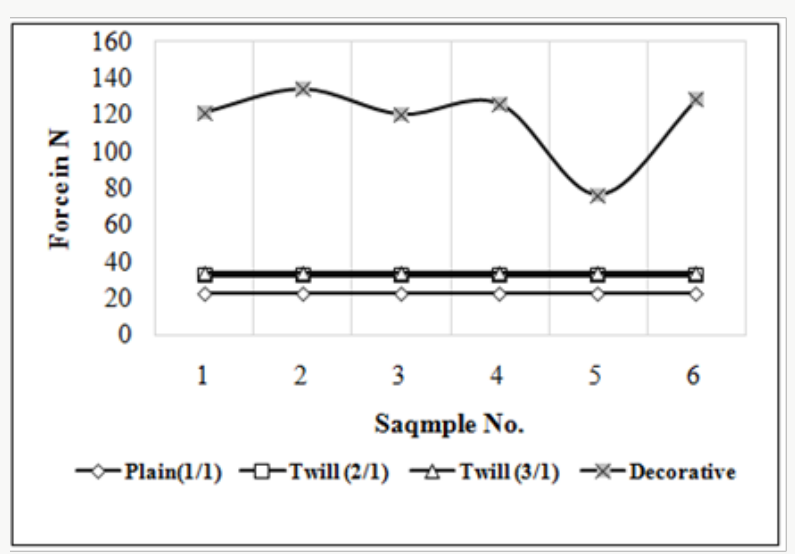

Figure 4: Warp way tear strength of denim fabrics.

The warp and weft way tearing strength express in $\mathrm{N}$ of all test specimen are presented in (Figures 4 \& 5) respectively. It is observed that the tear strength of decorative fabric in both warp and weft way is extensively higher than conventional denim fabrics. The absence of diagonal twill line and random weave float causing the remarkable improvement of tear strength of decorative denim in comparison to regular one.

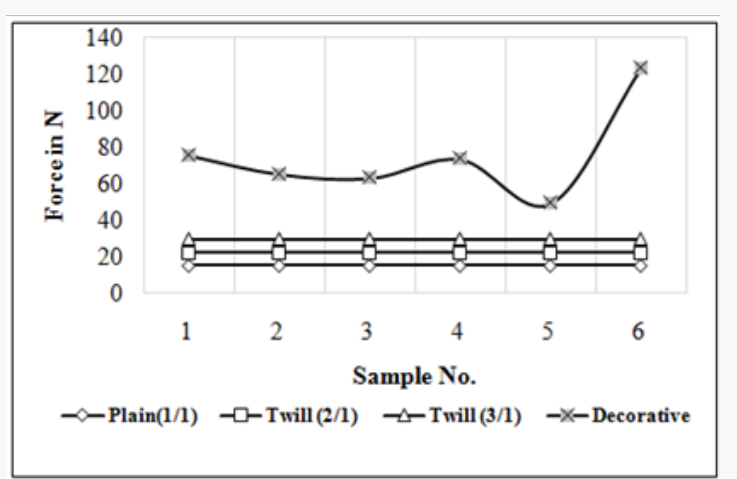

Figure 5: Weft way tear strength of denim fabrics.

\section{Assessment of Tensile Strength}

(Figures 6\& 7) illustrate the warp and weft way tensile strength of denim fabric. Almost similar value of tensile strength is found for decorative denim in comparison to basic denim both warp and weft way. However, some decorative specimen shows fluctuated strength value causing the weave structure variation. In addition, this is also observed that the more regular weave structure is responsible for better tensile strength.

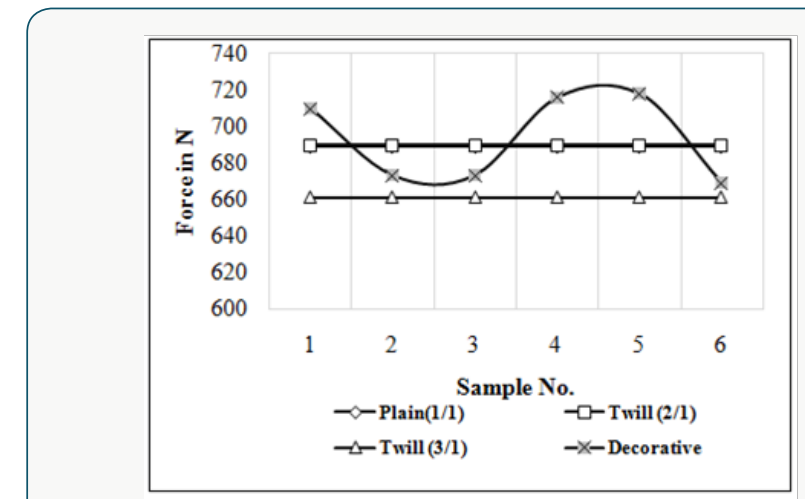

Figure 6: Warp way tensile strength of denim fabric.

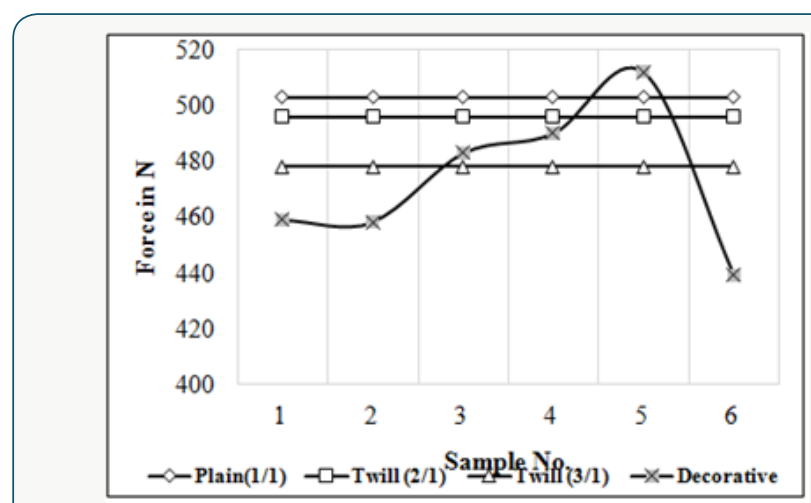

Figure 7: Weft way tensile strength of denim fabric. 


\section{Assessment of Length Wise Shrinkage \%}

The percentage of length wise shrinkage of standard and decorative denim cloths are shown in the (Figure 8). In comparison to the basic cloths the new developed dobby denim fabric exhibits the poor shrinkage property and the sample no 8 resulted the highest value i.e. 4.3 in length way. However the sample 1, 2 and 5 shows almost same value as plain structure lied between 0.9 and 0.3. The long float of decorative weave facilitates the substantial free space, which causes the more contraction of warp as a result the fabric length is decrease up to $4.3 \%$. On the other hand, the higher fabric contraction resulting the smoother surface good wrinkle property.

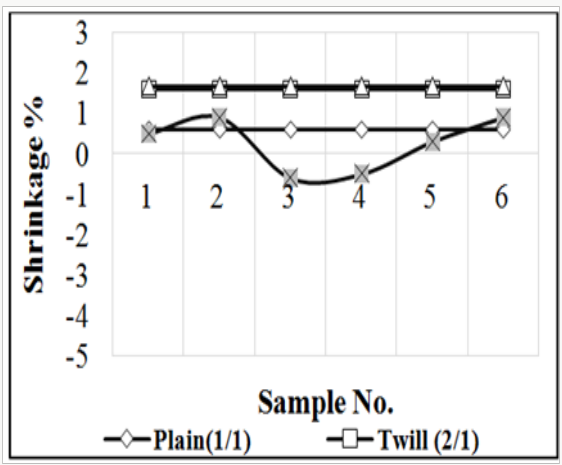

Figure 8: Comparison of length wise shrinkage \% of denim fabric.

\section{Assessment of Width Wise Shrinkage\%}

Figure 9 shows the width way shrinkage express in percentage of denim fabric. In width way direction there are a substantial decrement of fabric dimension is observed. The higher shrinkage percentage in width way create the huge loss of fabric however, the more yarn displacement resulting more soft fabric surface and attractive view.

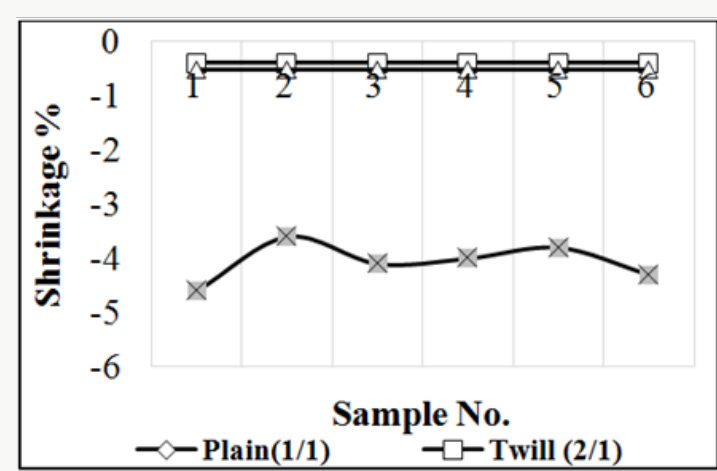

Figure 9: Comparison of width wise shrinkage \% of denim fabric.

\section{Assessment of Spirality \%}

The spirality of denim fabric is shown in (Figure 10). It is observed that the spirality of decorative denim is higher than the traditional denim; however, some exception is occurred. The long float of decorative denim resulting the loose structure as well as more displacement of yarn in fabric. In some cases the more spirality percentage makes the fabric surface more attractive and soft hand feel.

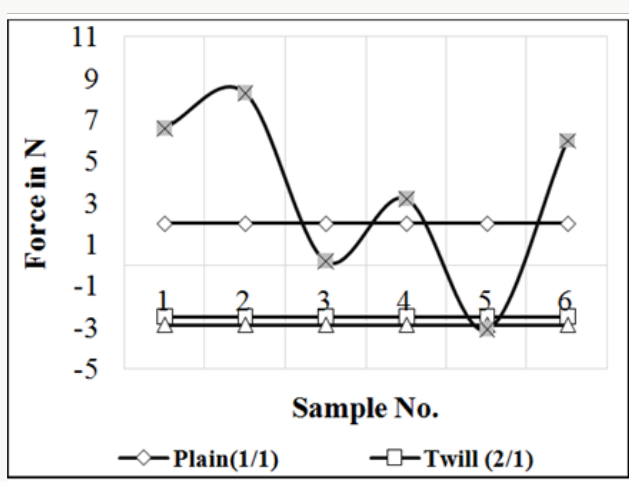

Figure 10: Comparison of spirality \% of denim fabric.

\section{Assessment of Fabric Weight}

The unit weight of both traditional and decorative denim fabric in oz/yd2are shown in (Figure 11). From the figure it is observed that the unit weight of decorative denim is higher than the regular denim due to bulky structure and long floating. The higher value of shrinkage and spirality percentage increases the fabric unit weight as well as the warp weft density and fabric thickness.

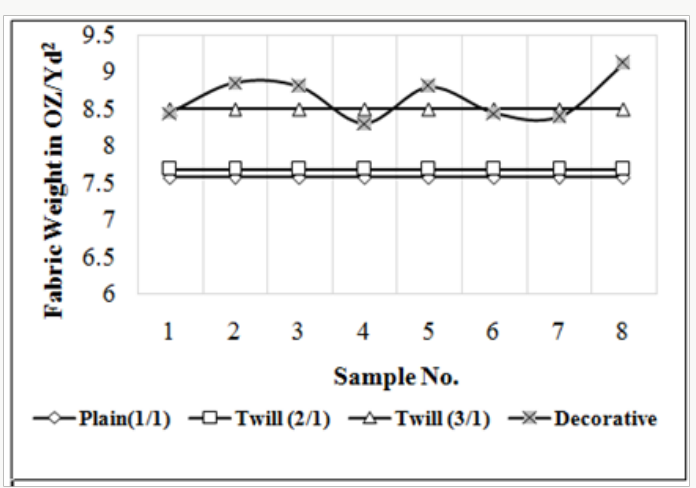

Figure 11: Comparison of fabric weight of denim fabrics

\section{Conclusion}

Denim garments are most desirable and fashionable wear for every stages of customer i.e. child, teenager, younger and adults. The demand of denim fabrics are increasing day by day as fashionable items. As for that it is essential to diversification of denim fabrics for decoration and fashioning according to the expectation of the innovative customer and market needs. The present study has tried to decorate denim fabric surface only replacing the conventional weave structure which lessen washing time and chemical. The developed denim fabric with decorative weave structure shows the more attractive fabric surface without applying heavy washing. In addition, the tear, tensile strength and fabric unit weight of decorative denim are more promising. However, more shrinkage and spirality are observed due to the loose structure and long float of decorative denim fabric. Finally, beautification of denim fabric by 
changing weave structure can be the step to minimize processing cost and encourage the eco-friendly textile processing.

\section{References}

1. MA Razzaque (2004) Garment \& Textile Merchandising, $1^{\text {st }}$ edn, Dhaka: Popular Publications.

2. M Khan, M Mondal, A Alam, M Hossain (2012) Modification of Denim Garment with the Treatment of Bleaching Powder. Canadian Journal on Chemical Engineering \& Technology 3(2): 30-36.

3. S Lu (2010) Effect of alkaline treatment on the properties of denim woven fabric made from torque free yarn and conventional yarn, Hong Kong.

4. D Upadhyay, R Ambavale (2015) A Study on Preference with Reference to Denim Jeans in Female Segment in Ahmadabad City, Ahmadabad

5. S Garaniya, PAI Thakkar (2013) Comparison of some of denim fabric properties produced with different weft. International Journal for Scientific Research \& Development 1(3): 548-550.
6. MY Yoon (2005) Denim finishing with enzymes. International Dyer 16(11): 16-19.

7. S. Mezarciöz, M Toksöz (2014) Investigation of effect of special washing processes on denim fabrics'properties. Journal of Textile \& Apparel 24(1): 86-95.

8. D Arjun, J Hiranmayee, MN Farheen (2013) Technology of Industrial denim washing: Review. International journal of industrial engineering \& technology 3(4): 25-34.

9. L Heikinheimo, J Buchert, A Miettinen Oinonen, P Suominen (2000) Treating denim fabrics with Trichoderma reesei cellulases. Textile Research Journal 70(11): 969-973.

10. MD Teli, AR Khare, R Chakrabarti (2008) Dependence of yarn and fabric strength on the structural parameters. Autex Research Journal 8(3): 6367.

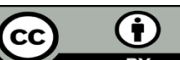

This work is licensed under Creative Commons Attribution 4.0 License

To Submit Your Article Click Here: Submit Article

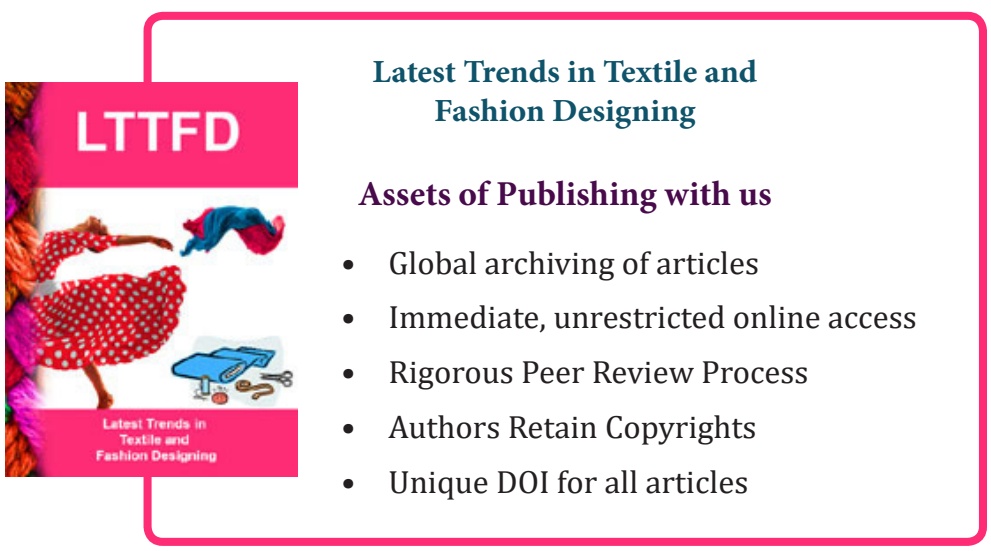

